\title{
Maternal folate status as a risk factor for autism spectrum disorders: a review of existing evidence
}

\author{
Elizabeth A. DeVilbiss ${ }^{1, *}$, Renee M. Gardner ${ }^{2}$, Craig J. Newschaffer ${ }^{1,3}$ and Brian K. Lee ${ }^{1,3}$ \\ ${ }^{1}$ Department of Epidemiology and Biostatistics, Drexel University School of Public Health, Philadelphia, PA 19104, USA \\ ${ }^{2}$ Department of Public Health Sciences, Division of Public Health Epidemiology, Karolinska Institutet, 17177 Stockholm, Sweden \\ ${ }^{3}$ AJ Drexel Autism Institute, Philadelphia, PA 19104, USA \\ (Submitted 2 March 2015 - Final revision received 9 May 2015 - Accepted 2 June 2015 - First published online 5 August 2015)
}

\section{Abstract}

Emerging evidence from epidemiological studies supports the notion that maternal folate status regulated by dietary and genetic factors early in pregnancy may influence the risk of autism spectrum disorders (ASD). In this review, we provide an overview of what is known about the role of folate in the aetiology of neurodevelopmental disorders; summarise relevant biological, genetic and epigenetic mechanisms; and synthesise the evidence from human observational studies and randomised controlled trials that have examined the relationship between maternal folate and ASD or related traits. Much of the existing literature on this topic is subject to limitations such as potential confounding by healthy behaviours and other dietary factors, and exposure assessed within limited exposure windows. As the existing evidence is inconclusive, further research remains to be conducted in order to verify this hypothesis. Complete assessment of maternal functional folate status through the pre- and peri-conceptional periods requires biological measurement of folate, vitamin $\mathrm{B}_{12}$ and homocysteine and genetic variants involved in one-carbon metabolism and epigenetic mechanisms. In addition to more complete assessment of maternal functional folate status, careful consideration of potential confounding is warranted.

Key words: Autism: Epigenetics: Folic acid: Neurodevelopment: Pregnancy

Autism spectrum disorders (ASD) are neurodevelopmental disorders characterised by impaired social function, abnormal communication and repetitive or unusual behaviour ${ }^{(1)}$. Although the measured prevalence of ASD was no greater than five per 10000 individuals in the 1980s, estimated rates in US surveillance populations have increased to one in sixty-eight children in $2010^{(2)}$. Recent genetic and epidemiological studies suggest that the heritability of ASD is approximately $50 \%^{(3,4)}$, indicating that non-heritable risk factors contribute to a substantial proportion of ASD risk.

Recent epidemiological studies ${ }^{(5,6)}$ have suggested a possible link between maternal folate status during pregnancy and risk of ASD in children. As folate cannot be synthesised by humans and is entirely derived from dietary sources, folate status can be modified through increased intake of folate-rich foods such as leafy green vegetables, folic acid (FA) supplements or fortification of the food supply. This raises the intriguing prospect that, much like with neural tube defects ${ }^{(7,8)}$, the incidence of ASD may be decreased through interventions that enrich maternal folate status. This review aims to summarise the biological, genetic and epidemiological evidence linking folate status and the risk of ASD. In addition, we discuss the research challenges that remain to be addressed before any firm conclusion can be drawn about the possible link between maternal folate status and risk of ASD.

Neurodevelopment is influenced by deoxyribonucleic acid methylation

Documentation of problems in ASD core areas such as communication, socialisation and attention in children $<12$ months of age $^{(9,10)}$ supports the notion that disruption of neurodevelopmental processes during the pre- and perinatal period may contribute to ASD. In particular, epigenetic modifications during peri-conception are increasingly recognised as having lasting developmental implications with regard to $\mathrm{ASD}^{(11)}$. One especially relevant epigenetic process crucial to neurodevelopment is DNA methylation, which influences gene expression through the methylation of cytosine residues in CPG dinucleotides. DNA methylation depends on the availability of dietary methyl donors such as folate, choline and methionine, which are interrelated through one-carbon metabolism. Changes to the availability of folate or other methyl donors can affect DNA methylation capacity, with potential downstream neurodevelopmental consequences.

Abbreviations: ASD, autism spectrum disorders; FA, folic acid; MTHFR, methylene tetrahydrofolate reductase.

*Corresponding author: E. A. DeVilbiss, email ead77@drexel.edu 
During the peri-conceptional period, methylation patterns of the genome (with the exception of imprinted genes) are first established, beginning with de-methylation of maternal and paternal DNA, followed by re-methylation of the combined genome. De-methylation occurs in the pre-implantation embryo, and it is generally completed by the 16- or 32-cell morula stage, about $4 \mathrm{~d}$ after fertilisation. Methylation levels then increase markedly through the blastocyst stage, about $5 \mathrm{~d}$ post fertilisation ${ }^{(12,13)}$. Thus, even before a pregnancy can be confirmed, a high concentration of dietary methyl donors is required to establish epigenetic patterns in the cells of the developing embryo ${ }^{(14)}$.

Another critical window occurs during early pregnancy, in which the brain rapidly begins to develop. In the 1st month of gestation, the central nervous system begins to form with neurogenesis and cell migration occurring in the forebrain, midbrain and hindbrain ${ }^{(15)}$. Neurogenesis in most cortical and subcortical structures occurs between 5 and 25 weeks of gestation $^{(15)}$. The development of functional neuron networks ${ }^{(16)}$ requires high concentrations of methyl donors for cellular differentiation $^{(17)}$, as DNA methylation is essential for individual cell viability ${ }^{(18,19)}$. Early modifications in DNA methylation that cause developing brain cells to deviate from proper differentiation can result in irreversible reductions or expansions of neuron pools ${ }^{(16)}$. Consequently, epigenetic dysregulation during the period when brain organisation develops could result in alterations in brain connectivity ${ }^{(20-22)}$.

\section{Dietary and genetic determinants of folate status affect deoxyribonucleic acid methylation capacity in the brain}

Embryonic DNA can become hypomethylated if maternal plasma does not contain sufficient levels of methyl donors such as folate and cofactors such as vitamin $\mathrm{B}_{12}$ at critical periods in development ${ }^{(23)}$. Dietary deficiency of methyl donors has been associated with DNA hypomethylation in the brains ${ }^{(24)}$ of rats and in genes controlling brain development in rat fetuses ${ }^{(20)}$. For example, a maternal diet low in choline, another dietary methyl donor, resulted in global DNA hypomethylation and increased expression of genes that turn off cell cycling and promote early differentiation in the hippocampus of fetal mice $^{(20)}$

Although environmental exposures (e.g. decreased dietary folate intake) can result in embryonic hypomethylation, hypomethylation also can occur via genetic regulation of processes relevant to both folate metabolism and DNA methylation. For example, functional hypomethylation can result from polymorphisms in the offspring gene coding for protein readers of DNA methylation patterns, namely methyl-CpG-binding protein 2 (MeCP2), a methyl-binding domain protein. This can have important structural and functional consequences, as neurons without functional MeCP2 in the cortex have been found to have significantly smaller dendritic arbours in both humans ${ }^{(21)}$ and mice ${ }^{(22)}$

Another example of genetic regulation is with 5methyltetrahydrofolate (5-MTHF), the functional methyl donor form of folate, which is synthesised from a folate derivative by the enzyme methylene tetrahydrofolate reductase (MTHFR). Human carriers of the MTHFR C677T and A1298C polymorphisms have lower enzyme activity, reducing the production of 5-MTHF and the ability of folate to function as a methyl donor in the production of methionine and subsequent DNA methylation ${ }^{(25)}$. Interestingly, a meta-analysis of eight studies on the relationship between child MTHFR polymorphisms and $\mathrm{ASD}^{(26)}$ reported that the $\mathrm{C} 677 \mathrm{~T}$ polymorphism was only associated with ASD in children living in countries without food fortification. The dependence of a genetic association on a background of the dietary environment is suggestive evidence that gene-environment interactions are instrumental in pathways linking folate status with child ASD.

Collectively, the existing human and animal research on onecarbon metabolism suggests that maternal folate status could be a biologically plausible risk factor for ASD through its impact on DNA methylation.

\section{Other pathways by which folate influences neurodevelopment}

In addition to the effects on DNA methylation, folate status can influence neurodevelopment through multiple other pathways. Mutations in the folate receptor 1 (FOLR1) gene coding for folate receptor $\alpha(\mathrm{FR} \alpha)$ have been associated with severe hypomyelination in the brains of affected patients ${ }^{(27)}$. Because cellular uptake of metabolised folate (MTHF) is mediated by FR $\alpha$ (along with other proteins), functional mutations in FOLR1 also result in systemic folate deficiency ${ }^{(27)}$. Moreover, the folate cycle is peripherally involved in the creation of essential phospholipids (e.g. phosphatidylcholine) and neurotransmitters (e.g. serotonin) ${ }^{(28)}$. Therefore, reduced availability of dietary methyl donors during key exposure windows could interfere with the production of these critical neurodevelopmental elements. Children with ASD have been found to exhibit dysregulated serotonergic function ${ }^{(29)}$, as well as lower levels of phosphatidylcholine in plasma, in comparison with typically developing children $^{(30)}$. Finally, as folate is also involved in DNA synthesis, folate deficiency may result in deficient DNA repair, inducing DNA damage and neuronal death ${ }^{(31)}$. This is consistent with work demonstrating that dietary maternal FA deficiency in mice affects the development of the neocortex and other regions of the brain by reducing the number of progenitor cells through its influence on cell mitosis and apoptosis ${ }^{(32)}$

Although a comprehensive review examining folate and altered neurodevelopment is beyond the scope of this paper, other authors have reviewed such literature in detail ${ }^{(33,34)}$.

\section{Human studies linking maternal folate and autism spectrum disorders and related traits}

\section{Methods}

To identify studies examining maternal folate status and autism or related traits specified as such, PubMed was first searched for the terms (folic acid or folate) (autis*) on 21 January 2014, with no date range specified. This search was repeated periodically through 15 April 2015, to ensure inclusion of new relevant studies. As of 15 April 2015, this search produced 136 citations. 
Criteria for inclusion in the review were original research articles examining FA or folate exposure during pregnancy, with autism or related traits as outcomes in the offspring. Studies (or aspects of manuscripts ${ }^{(35)}$ ) examining multivitamins without specific mention of FA were excluded. Additional exclusion criteria were biochemical studies and/or those focused on understanding biological mechanisms, animal studies and ecological studies, the lattermost because of the lack of rigour and inability to draw causal inference. Of the search results, four citations remained after application of inclusion and exclusion criteria (Fig. 1).

Because of the existence of relevant literature on ASD traits not designated as such, literature for review was also selected from references of included (five additional studies) and excluded search results (one additional study). As many references examined numerous outcomes, autism outcomes experts were consulted to identify the most ASD-relevant outcomes (executive function, communication and social competence) within the ten articles selected for review. Included studies were evaluated based on quality of measured exposure and outcome, control for relevant confounders, biases and other analytical issues.

The human evidence linking maternal folate status with ASD and related traits comes from various studies distinguished by study design (observational $v$. randomised), how folate status is measured (e.g. self-reported folate or supplement intake $v$. biomarker measurement) and study outcome (clinical diagnoses of ASD $v$. ASD-related traits). We discuss this evidence in the following sections, organised by these characteristics. All studies are summarised in Table 1.

\section{Observational studies of maternal folate and autism spectrum disorders}

To date, there are only two published epidemiological studies examining maternal folate status during pregnancy and diagnoses of ASD. Despite differences in size, populations and study designs, an American case-control study by Schmidt et $a l .{ }^{(5)}$ and a Norwegian cohort study by Suren et $a l .{ }^{(6)}$ reported similar protective associations for maternal FA intake in the peri-conceptional period and early pregnancy, and children's risk of ASD. The case-control study featured 429 cases and 278 controls, whereas the cohort study featured 85176 children, of whom only 270 had been diagnosed with ASD. The OR for the case-control study ${ }^{(5)}$ was $0.62(95 \%$ CI $0.42,0.92)$ for a mean daily FA intake of $\geq 600 v$. $<600 \mu \mathrm{g}$ in the 1st month of pregnancy, whereas the cohort study ${ }^{(6)}$ estimated an OR of 0.61 (95\% CI 0.41, 0.90) for FA supplementation in the month before and first 2 months of pregnancy compared with no supplementation. Furthermore, the case-control study found that the reduced risk for FA intake $\geq 600 \mu \mathrm{g}$ was only evident for mothers and/or children having the MTHFR C677T variant ${ }^{(5)}$.

Although these studies support that maternal folate status may influence ASD risk, there are important considerations. For example, the ASD prevalence in the Norwegian study was $0.3 \%$. Given that $1 \%$ is the generally accepted figure for worldwide ASD prevalence ${ }^{(43)}$, this disparity is a strong indication of case underascertainment that may influence results. The potential for ascertainment bias is supported by evidence that mothers of severely affected children had lower response rates.

Another limitation is that both studies relied on self-reported maternal intake of FA. Self-reports can introduce recall or reporting bias, although the concern is less in the prospectively designed Norwegian study, which assessed peri-conceptional FA use at 18 weeks of gestation, well before the birth of the child ${ }^{(6)}$. To what degree such self-reports reflect actual folate exposure is unclear, as no biomarkers were available in these studies. In addition, social, economic, behavioural and environmental factors can influence self-reported vitamin supplementation ${ }^{(44,45)}$. For instance, in a study of childbearing-age women in the USA,

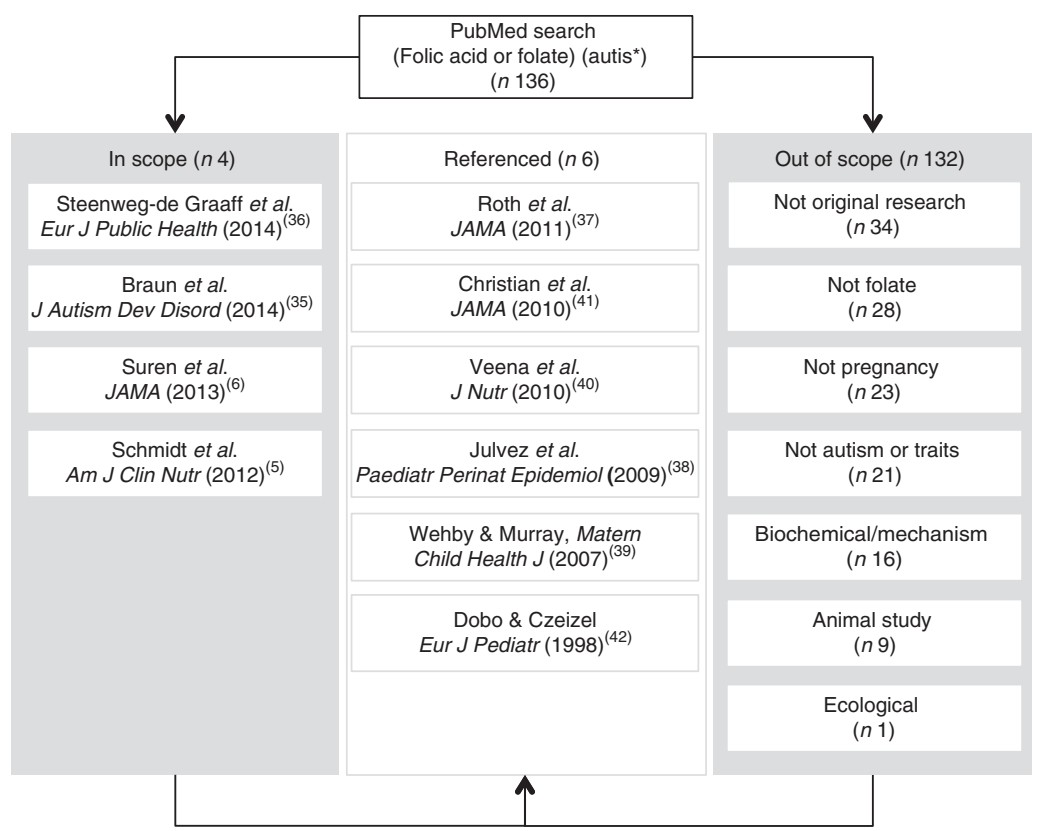

Fig. 1. Derivation of reviewed literature. 
Table 1. Epidemiologic studies assessing maternal folate status and autism spectrum disorders (ASD) or ASD-related traits

\begin{tabular}{|c|c|c|c|c|}
\hline Reference (country) & $\begin{array}{l}\text { Study design and } \\
\text { number of children }\end{array}$ & Exposure assessment & Outcome & Results \\
\hline \multicolumn{5}{|c|}{ Self-reported maternal folate status and ASD diagnosis } \\
\hline $\begin{array}{l}\text { Suren et al. }{ }^{(6)} \\
\text { (Norway) }\end{array}$ & $\begin{array}{l}\text { Cohort study of } \\
85176 \text { (114 AD; } \\
56 \text { Asperger; } \\
100 \text { PDD-NOS) }\end{array}$ & $\begin{array}{l}\text { FA supplementation } 4 \text { weeks } \\
\text { before to } 8 \text { weeks after } \\
\text { conception; questionnaire at } \\
18 \text { weeks of gestation }\end{array}$ & $\begin{array}{l}\text { AD, with or without language } \\
\text { delay at } 36 \text { months; Asperger } \\
\text { syndrome; PDD-NOS }\end{array}$ & $\begin{array}{l}\text { Children of FA users } v \text {. non-users } \\
\text { had } 0.61 \text { ( } 95 \% \mathrm{Cl} 0.41,0.90 \text { ) } \\
\text { times the odds of AD; protective } \\
\text { association only in AD with } \\
\text { language delay (OR } 0.49 \text {; } \\
95 \% \mathrm{Cl} 0.25,0.99 \text { ) but not in } \\
\text { AD without language delay } \\
\text { (OR } 0.91 ; 95 \% \mathrm{Cl} 0.46,1.81 \text { ); } \\
\text { FA use not associated with } \\
\text { Asperger or PDD-NOS }\end{array}$ \\
\hline $\begin{array}{l}\text { Schmidt et al. }{ }^{(5)} \\
\text { (USA) }\end{array}$ & $\begin{array}{l}\text { Case-control study of } \\
\quad 429 \text { ASD; } 278 \text { TD; } \\
130 \text { DD }\end{array}$ & $\begin{array}{l}\text { Dietary and vitamin FA intake } \\
3 \text { months before pregnancy and } \\
\text { in the } 1 \text { st month of pregnancy; } \\
\text { questionnaire at } 2-5 \text { years after } \\
\text { birth }\end{array}$ & $\begin{array}{l}\text { ASD defined by Autism } \\
\text { Diagnostic Interview-Revised } \\
\text { and the Autism Diagnostic } \\
\text { Observation Schedule-Generic }\end{array}$ & $\begin{array}{l}\text { Children of mothers taking } \geq 600 \\
v .<600 \mu \mathrm{FA} \text { in the } 1 \mathrm{st} \text { month } \\
\text { of pregnancy had reduced odds } \\
\text { of ASD (OR } 0.62 ; 95 \% \mathrm{Cl} 0.42 \text {, } \\
0.92 \text { ). In stratified analyses, the } \\
\text { association was only evident } \\
\text { when the mother and/or child } \\
\text { had the MTHFR C677T variant } \\
\text { genotype }\end{array}$ \\
\hline
\end{tabular}

Self-reported maternal folate status and ASD-related traits
Steenweg-de
Graaff et al. ${ }^{(36)}$
(The Netherlands)
Cohort study of 3893 FA supplement use and when children initiated; questionnaire at $<18$ weeks of gestation

$\begin{array}{cc}\begin{array}{c}\text { Roth et al. } \\ \text { (Norway) }\end{array} & \begin{array}{c}\text { Cohort study of } \\ 38954 \text { childre } \\ \text { (204 severe } \\ \text { language delay) }\end{array} \\ \\ \begin{array}{c}\text { Julvez et al. }{ }^{(38)} \\ \text { (Spain) }\end{array} & \begin{array}{c}\text { Cohort study of } \\ 420 \text { children }\end{array}\end{array}$

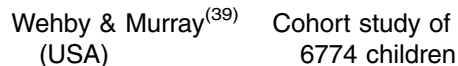
FA supplementation 4 weeks before to 8 weeks after conception; questionnaire at 17 weeks of gestation gestation
Autistic traits at 6 years - Social Responsiveness Scale (SRS) short form, Pervasive Developmental Problems subscale of the Child Behavior Checklist

Severe language delay at 3 years - MacArthur Communication Development Inventory UK short form
Use of FA associated with lower SRS scores: 'pre-conception start' $v$. 'no use': -0.042 , $95 \% \mathrm{Cl}-0.068,-0.017$ 'Start $<10$ week' $v$. 'no use': $-0.041,95 \% \mathrm{Cl}-0.066,-0.016$ 'Start $>10$ week' $v$. 'no use': $-0.057,95 \% \mathrm{Cl}-0.089,-0.025$

Maternal FA only (OR 0.55; $95 \%$ $\mathrm{Cl} 0.35,0.86$ ) or in combination with other supplements (OR $0.55 ; 95 \% \mathrm{Cl} \mathrm{0.39,0.78)}$ associated with reduced risk of severe language delay. Supplements without FA not associated with severe language delay (OR 1.04; $95 \% \mathrm{Cl} 0.62,1.74)$

FA supplementation at the end of Verbal competence and executive FA use associated with higher the first trimester; questionnaire function at 4 years (McCarthy at a median of 12.4 weeks of Scales of Children's Abilities)

Social competence at 4 years (California Preschool Social Competence Scale)

FA supplementation for at least $3 \mathrm{~d} /$ week during the 3 months before becoming aware of pregnancy through first trimester; questionnaire at $\geq 6$ months after birth
Personal-social and language domains at 3 years (Denver developmental screening) verbal $(3.98 \mathrm{pt}, 95 \% \mathrm{Cl} 0.66$, 7.31) and social competence (3.97 pt, $95 \%$ Cl 0.81, 7.14) scores. Use of vitamins without FA associated with improvements in verbal $(6.52 \mathrm{pt}$, $95 \% \mathrm{Cl} 0.46,12.58)$, but not social competence scores (3.73 pt, $95 \% \mathrm{Cl}-1.86,9.32$ ). FA use not associated with executive function scores

FA use associated with somewhat poorer performance within the personal-social domain, compared with non-use of FA (OR 1.78; $95 \% \mathrm{Cl} 0.94,3.38$ ). No associations observed between FA use and language development (OR 0.91; $95 \% \mathrm{Cl}$ $0.55,1.50$ )

Folate concentrations associated with slightly higher SRS scores $(0.6 / \mathrm{sD}, 95 \% \mathrm{Cl} 0.3,1.5)$ and SRS scores $\geq 60$ (OR 1.42; $95 \% \mathrm{Cl} \mathrm{0.81,} \mathrm{2.49)}$ 
Table 1 Continued

\begin{tabular}{|c|c|c|c|c|}
\hline Reference (country) & $\begin{array}{l}\text { Study design and } \\
\text { number of children }\end{array}$ & Exposure assessment & Outcome & Results \\
\hline $\begin{array}{l}\text { Steenweg-de } \\
\text { Graaff et al. }{ }^{(36)} \\
\text { (The Netherlands) }\end{array}$ & $\begin{array}{l}\text { Cohort study of } \\
3893 \text { children }\end{array}$ & $\begin{array}{l}\text { Maternal plasma folate at a } \\
\text { median of } 13.2 \text { weeks of } \\
\text { gestation ( } 90 \% \text { range: } \\
10.5-17.2 \text { weeks) }\end{array}$ & $\begin{array}{l}\text { Autistic traits at } 6 \text { years - SRS } \\
\text { short form, Pervasive } \\
\text { Developmental Problems } \\
\text { subscale of the Child Behavior } \\
\text { Checklist }\end{array}$ & $\begin{array}{l}\text { Folate concentrations not } \\
\text { associated with SRS scores } \\
(-0.004 \mathrm{pts} / 1 \mathrm{SD} \text { increase; } \\
95 \% \mathrm{Cl}-0.013,0.004) \text { or } \\
\text { odds of probable ASD } \\
\text { (OR } 1.03 ; 95 \% \mathrm{Cl} 0.76,1.39)\end{array}$ \\
\hline $\begin{array}{l}\text { Veena et al. }{ }^{(40)} \\
\quad \text { (India) }\end{array}$ & $\begin{array}{l}\text { Cohort study of } \\
536 \text { children }\end{array}$ & $\begin{array}{l}\text { Maternal plasma folate at a mean } \\
\text { of } 30(\mathrm{SD} 2) \text { weeks of gestation }\end{array}$ & $\begin{array}{l}\text { Language production at } 9-10 \\
\text { years - A Developmental } \\
\text { Neuropsychological } \\
\text { Assessment }\end{array}$ & $\begin{array}{l}\text { Folate concentrations not } \\
\text { associated with language } \\
\text { production scores }\end{array}$ \\
\hline \multicolumn{5}{|c|}{ Randomised trials of FA supplementation and ASD-related traits } \\
\hline $\begin{array}{l}\text { Christian et al. }{ }^{(41)} \\
\quad \text { (Nepal) }\end{array}$ & $\begin{array}{l}\text { Cohort follow-up of } \\
676 \text { children }\end{array}$ & $\begin{array}{l}\text { Assignment of daily supplement } \\
\text { use at a mean of } 11 \text { weeks } \\
\text { (sD } 5 \cdot 1 \text { ) of gestation: } \\
\text { FA + iron + vitamin A, } \\
\text { FA + iron + zinc + vitamin A, } \\
\text { FA + iron + zinc + vitamin } \\
A+\text { multiple micronutrients, } \\
\text { control of vitamin A only }\end{array}$ & $\begin{array}{l}\text { Executive functioning at } 7-9 \\
\text { years: Stroop numbers test, } \\
\text { backward digit span from the } \\
\text { Wechsler memory scale, } \\
\text { go/no-go test }\end{array}$ & $\begin{array}{l}\text { Executive function scores } \\
\text { improved in the FA + iron group } \\
\text { relative to controls for Stroop } \\
\text { test (failure proportion }-0.14 \text {, } \\
95 \% \mathrm{Cl}-0.23,-0.04) \text { and } \\
\text { backward digit span }(0.36, \\
95 \% \mathrm{Cl} 0.01,0.71) \text {, but } \\
\text { not for go/no-go test }\end{array}$ \\
\hline $\begin{array}{l}\text { Dobo \& Czeizel }{ }^{(42)} \\
\text { (Hungary) }\end{array}$ & $\begin{array}{l}\text { Cohort follow-up of } \\
625 \text { children }\end{array}$ & $\begin{array}{l}\text { Assignment of multivitamin with } \\
\text { FA or placebo-like trace } \\
\text { element at least } 1 \text { month before } \\
\text { conception through } 2 \text { months of } \\
\text { gestation }\end{array}$ & $\begin{array}{l}\text { Speaking, communication and } \\
\text { sociability at } 2 \text { years - } \\
\text { Developmental Quotient } \\
\text { Speech and sociability at } \\
6 \text { years - Goodenough man } \\
\text { drawing test }\end{array}$ & $\begin{array}{l}\text { No differences in developmental } \\
\text { scores in children of mothers } \\
\text { assigned to take a multivitamin } \\
\text { with FA compared with trace } \\
\text { element controls }\end{array}$ \\
\hline
\end{tabular}

AD, autistic disorder; PDD-NOS, pervasive developmental disorder not otherwise specified; FA, folic acid; TD, typically developing; DD, developmental delay.

women of normal weight were more likely to use supplements with FA, compared with women who were overweight or obese $^{(46)}$. However, this difference was not statistically significant. In a study of the Kaiser Permanente Medical Care Program in Northern California, alcohol users were less likely to take multivitamins than non-alcohol users during pregnancy ${ }^{(47)}$. Data from the National Maternal and Infant Health Survey indicate that regular multivitamin users before and after pregnancy were more likely to be older, white, married, have a wanted pregnancy, less likely to consume six or more drinks per week during pregnancy and have greater levels of education and income than mothers not using multivitamins regularly ${ }^{(48)}$. In another study maternal FA use in the peri-conceptional period was associated with increased socio-economic status ${ }^{(49)}$. These factors can be difficult to completely adjust for in observational studies ${ }^{(44)}$.

Exposure assessment in the Norwegian study was of FA as a single nutrient formulation. Although this study had information on multivitamin usage available, it did not explicitly account for this in analyses, indicating that FA content of multivitamins was $<400 \mu \mathrm{g}$ (the amount in single nutrient formulations) in Norway at the time of the study. The exclusion of multivitamin usage from statistical analyses leaves the possibility of confounding by other dietary factors, as FA and multivitamin use may be positively correlated. For example, increased maternal intake of iron ${ }^{(50)}$ or $n-3$ fatty acids ${ }^{(51)}$ has been associated with a reduced risk of ASD. In a recent study, FA use in the peri-conceptional period was associated with a higher intake of other B vitamins ${ }^{(49)}$. However, the Norwegian study found that fish oil supplementation was not similarly associated with a reduced risk of
ASD, suggesting that maternal healthy behaviours, such as multivitamin use, were not responsible for the observed protective effect observed for $\mathrm{FA}^{(6)}$.

The American case-control study considered both supplementary FA and dietary folate from select high concentration sources, but not total dietary folate intake. This study did examine potential confounding by other nutrients and found that adjustment for total amounts of other nutrients from dietary and supplementary sources actually strengthened the reduction in risk between FA and ASD in the 1st month of pregnancy ${ }^{(5)}$.

It is important to emphasise the exposure windows assessed by these two studies. The protective association reported by the prospective Norwegian study was of FA use in the month before conception and in the first 2 months of pregnancy. This study also examined FA use at 22 weeks of gestation and found no association. Meanwhile, the American case-control study assessed exposure in the 1 month of pregnancy only. It is difficult to ascertain how the use of different exposure windows influenced study results because of their other methodological differences. However, despite their limitations, the studies' similar OR were strong and robust to confounder control and sensitivity analyses.

\section{Observational studies of self-reported maternal folate and autism spectrum disorder traits}

In contrast to the limited evidence concerning maternal folate status and ASD diagnoses, four prospective cohort studies have linked self-reported maternal folate with traits related to autism, such as social competence and verbal abilities, but not to 
executive function. However, results are not wholly in agreement.

These cohort studies differ in their selection of FA exposure windows. Three studies assessed whether FA use had commenced before pregnancy ( 4 weeks before conception ${ }^{(37)}$, 3 months before becoming aware of pregnancy ${ }^{(39)}$ or preconception $^{(36)}$ ), whereas the remaining study limited assessment of the exposure window to after pregnancy had been established - at the end of the first trimester ${ }^{(38)}$.

Studies assessing FA use before pregnancy reported a reduced risk of severe language delay at 3 years ${ }^{(37)}$, lower autistic trait scores (less autistic traits) at 6 years ${ }^{(36)}$, but also unfavourable development of the personal-social domain at 3 years of age ${ }^{(39)}$. The research investigating FA use only during pregnancy reported improved verbal and social competence, but not executive functioning scores at 4 years ${ }^{(38)}$. Measures used to assess these outcomes are provided in Table 1.

A concern of many of the studies examining folate and ASD is that self-report of folate may be a poor surrogate for biological folate status. To that end, in the Generation R Study, although FA users had higher plasma folate concentrations at a median of 13 weeks of gestation ${ }^{(36)}$, associations between maternal plasma folate and ASD traits did not persist as they had for selfreport of FA supplementation. These discordant results could be related to the timing of biological sampling, given that the most crucial period for dietary methyl donor availability is likely in the peri-conceptional period. Therefore, if folate were indeed protective against ASD, peri-conceptional folate levels would be more relevant to measure. This also may indicate that residual confounding may be partly responsible for the observed protective effect, in that health-related behaviours are more common among women who take supplements.

In particular, one health-related behaviour that could confound observed protective effects of FA on developmental outcomes is dietary intake of nutrients other than $\mathrm{FA}^{(49)}$. This is a possibility in the study in which improvements in verbal and social competence scores were noted for children of mothers using multivitamins both with $(n 244)$ and without FA $(n 28)^{(52)}$. A second study reported significant associations between multivitamin and/or mineral use and reduced risk on the personalsocial and language scales, but suggested a relationship between maternal FA use and unfavourable development on the personal-social scale ${ }^{(39)}$. This may indicate that a component of multivitamins other than FA may be responsible for the observed protective association. Alternatively, as $83 \%$ of individuals in this latter study reported multivitamin and/or mineral use and only $3.2 \%$ of the total sample in the study reported FA use, this is perhaps suggestive of confounding by indication among the small sample of FA users. Conversely, the Norwegian study ${ }^{(37)}$ that examined severe language delay reported results both for mothers taking FA only and those taking it in combination with other supplements, and reported similar OR (FA only: OR 0.55; $95 \%$ CI 0.35, 0.86; FA with other supplements: OR $0.55 ; 95 \%$ CI $0.39,0.78)$. A fourth study did not consider the use of other vitamins in their analyses ${ }^{(36)}$.

Results from these studies were inconsistent, but overall tended to support a protective effect. Self-report of FA supplementation in early pregnancy, either alone or in combination with other vitamins, was associated with reduced risk of ASDrelated traits in three of the four studies, whereas a harmful association was noted in one of the studies. However, because of potential confounding by other nutrients, two of the three studies reporting protective associations cannot specifically ascribe this protection to FA. In addition, if health-related behaviours are incompletely controlled in these studies, observed associations may be biased because of residual confounding.

\section{Observational studies of maternal folate biomarker and autism spectrum disorder traits}

Three epidemiological studies of biologically ascertained maternal FA status and ASD traits were identified, one of which $^{(36,52,53)}$ was discussed in the preceding section. This study reported no association between maternal serum folate concentrations at a median of 13 weeks of gestation and child autistic traits ${ }^{(36)}$. Another study of 209 children reported a weak positive association between maternal whole blood folate concentrations at a mean of 16 weeks of gestation and Social Responsiveness Scale scores at $4-5$ years ${ }^{(35)}$. Within the domain of language production, an Indian study of 536 births reported that significant associations with maternal serum folate at $30 \pm 2$ weeks of gestation did not persist after adjustment ${ }^{(40)}$.

One advantage of these studies is that use of a biomarker for folate status mitigates the measurement error associated with subjective, self-reported measures. However, as previously described, assessment at different time periods may affect findings. As folate concentrations might be expected to be most similar within short time intervals, folate biomarkers measured later in pregnancy might be less correlated with peri-conceptional values than those measured earlier in pregnancy. Studies of FA usage patterns during pregnancy indicate that FA use is typically commenced within the first trimester ${ }^{(54-56)}$. It is thus not likely that maternal folate even at 13 weeks of gestation, the earliest of biomarker measurement of these three studies, is highly correlated with concentrations during the peri-conceptional period. Results of these studies may therefore not be as meaningful as those measuring maternal folate by the time of neural tube closure at 6 weeks of gestation ${ }^{(6,55)}$ or by development of basic brain structures at 5-10 weeks of gestation ${ }^{(57)}$.

In summary, the studies utilising biomarker measures of folate status do not consistently support an overall effect. A weak association was reported in the cohort assessing folate at 16 weeks of gestation, but reduced risks of ASD-related traits were not shown in the cohorts assessing maternal folate biomarkers at 13 and 30 weeks of gestation. However, given the timing of maternal folate biomarker measurement, these findings should be interpreted with caution.

\section{Folate supplementation and autism spectrum disorder characteristics: randomised trials}

Only two randomised trials have examined relationships between maternal FA supplementation and ASD traits. A Nepali study of 676 mother-child pairs reported higher executive functioning scores among 7- to 9-year-old children of women 
assigned to take daily iron/FA at a mean of 11 weeks of gestation, as compared with a control group assigned to take daily vitamin A supplements ${ }^{(41)}$. Similar findings were not reported among children of women assigned to take iron/ $\mathrm{FA} /$ zinc or iron/FA/zinc and micronutrients. Conversely, a Hungarian study of 625 mother-child pairs reported no meaningful differences in developmental scores assessing speech, communication and sociability at 2 and 6 years between children of mothers assigned to take multivitamins containing FA at least 1 month before conception through 2 months gestation, compared with children of mothers taking trace elements only ${ }^{(42)}$.

Although both studies were randomised, were of similar size and had a high rate of follow-up, the potential effect of FA could not be isolated in either study, as FA was taken with other vitamins. The multivitamin supplement in the Hungarian study ${ }^{(42)}$ contained zinc, which may have an inhibitory role, as evidenced by the Nepali ${ }^{(41)}$ study and as described in the literature ${ }^{(58,59)}$. As the Hungarian study most likely examined the most critical exposure window, results produced by this study may have been more meaningful had this study examined FA use independent of other vitamins.

\section{Trends in maternal folate status}

Although maternal folate status may be a biologically plausible risk factor for ASD, the collective evidence is not conclusive. Similar to ASD prevalence, maternal folate status has undergone a large change in recent decades, especially for countries that have adopted fortification. In the USA, the recommendation of $400 \mu \mathrm{g}$ of daily supplemental FA for women of childbearing age was put forth by the Centers for Disease Control and Prevention (CDC) in $1992^{(60)}$ and cereal fortification with folate began in $1996^{(61)}$. These actions resulted in an elevation in median serum folate from $12.6 \mu \mathrm{g} / \mathrm{l}$ in 1994 to $18.7 \mu \mathrm{g} / \mathrm{l}$ in $1998^{(61)}$. However, one possible misconception is that if maternal folate status was indeed causal for ASD, then the introduction of FA fortification in the 1990s should have resulted in a decline in ASD prevalence. Given the apparent rise in ASD prevalence in the USA over the past two decades, this would appear to contradict the possible role of maternal folate status.

Such ecologic thinking can be misleading, as it is more likely that changes in diagnostic practices, increased awareness and secular trends in other modifiable risk factors (e.g. advanced parental age) would offset any potentially beneficial effects of higher folate. In a California study ${ }^{(62)}$, approximately $26 \%$ of the increase in autism between 1992 and 2005 could be directly attributed to changes in diagnostic criteria. In particular, a separate study noted that higher autism prevalence was significantly associated with corresponding declines in the prevalence of mental retardation and learning disabilities between 1994 and $2003^{(63)}$. Within the California sample, it was estimated that $16 \%$ of the increase in autism prevalence over time was because of social influence and increased awareness ${ }^{(64)}$ and that $11 \%$ was attributable to the increase in parental age over time ${ }^{(65,66)}$. Thus, much of the increase in autism diagnoses within this California sample could be explained by changes in diagnostic practices, increased awareness and advanced parental age.
It has been suggested that the coincident timing of FA fortification with the beginning of the increase in measured autism prevalence $^{(67)}$ is not random, but rather the reflection of altered natural selection. The natural selection theory is that increased maternal folate status arising from these FA policy changes increased survival rates of infants with the MTHFR C677T polymorphism, who in the absence of increased FA in utero may have been miscarried. For example, there has been an increase in the frequency of the $\mathrm{C677T}$ allele and its homozygous genotype in individuals born in the last quarter of the twentieth century, as compared with the first three quarters ${ }^{(68)}$, with a greater frequency of this polymorphism in autistic individuals ${ }^{(69,70)}$. Whether this hypothesis carries weight remains to be examined.

\section{Recommendations for future research}

In this review, we examined the evidence that maternal folate status, especially early in pregnancy, might be involved in the development of ASD. The evidence to date is inconclusive, and highlights future research needs.

\section{More complete assessment of maternal functional folate status}

As folate intake is not the single determinant of functional folate status, studies with more complete assessment of this measure would allow for improved exposure assessment and clearer understanding of this aetiology.

With regard to folate measures, much of the epidemiological data on this topic use self-reported dichotomous data on multivitamin/FA intake as a surrogate for prenatal folate exposure. In contrast to self-reported measures, biological measures of folate status are not subjective, and therefore they are not subject to recall bias, as self-report may be. The use of serum or plasma folate as an indicator of folate status enables the exploration of potential dose-response effects, which is critical in establishing causality. Furthermore, given that one folate biomarker measurement is not necessarily indicative of a mother's folate status throughout pregnancy, serum folate measured at multiple time points before conception and throughout the first trimester would provide a more complete view of maternal folate status during this critical period of development. Repeated folate measurements may also help elucidate a critical window for adequate methyl donor availability, revealing potential mechanisms of ASD development.

It is important to note that only one of the studies reviewed in this paper measured maternal vitamin $\mathrm{B}_{12}{ }^{(40)}$, and none of the studies measured plasma homocysteine status in their analyses. Vitamin $\mathrm{B}_{12}$ and homocysteine are important components in the functional pathways connecting dietary methyl donors to neurodevelopment. Deficiency of vitamin $\mathrm{B}_{12}$ results in functional deficiency of folate, as the reaction cannot proceed in the absence of vitamin $\mathrm{B}_{12}$. For example, peri-conceptional vitamin $\mathrm{B}_{12}$ deficiency is linked with abnormal brain development in children ${ }^{(71)}$.

Homocysteine is a more complete indicator of methyl donor status and functionality, as folate is only one of three major dietary methyl donors. Dietary methyl donors are not functionally independent of one another, but rather changes in 
concentration of one donor result in compensatory changes in the others. Thus, the folate-ASD hypothesis may be further substantiated if links between other agents in the folate metabolic pathway are reported. Future studies should incorporate vitamin $\mathrm{B}_{12}$ and total homocysteine concentration measurements into their exposure assessments in the peri-conceptional period and in early pregnancy to account for the complex interdependency between these dietary factors.

\section{Incorporating genetic data}

To assess vulnerability to low maternal folate, to examine interactions between dietary and genetic factors and to understand the potential capability of maternal folate intake to offset genetic risk factors, further study is needed in which important genetic factors are sequenced. Most of the previously reviewed studies found in the literature did not explore associations between both dietary folate and genetic risk factors. A notable exception was the case-control study of FA intake and $\mathrm{ASD}^{(5)}$.

It is conceivable that if any of the enzymes on the pathway between folate and 5-MTHF acquire functional mutations, it may impair the ability of folate and/or FA to be converted to 5-MTHF and act as an efficient methyl donor. For example, polymorphisms in the MTHFR gene, which metabolises folate into a form capable of methyl donation, can reduce enzymatic activity, attenuating the ability of folate to function effectively. Other key enzymes on this pathway include dihydrofolate reductase, which converts synthetic FA and dihydrofolate into trihydrofolate $(\mathrm{THF})^{(72)}$, and serine hydroxymethyltransferase, which converts THF into 5,10-MTHF with vitamin $\mathrm{B}_{6}$ as a co-enzyme ${ }^{(73)}$. Functional mutations in enzymes related to the other two dietary methyl donors, choline and betaine, could also affect the action of folate because of compensatory changes that may occur through their interrelated metabolic pathways. Last, mutations in the $M e C P 2$ gene can prevent the MeCP2 protein product from binding to and interpreting DNA methylation marks, resulting in functional hypomethylation by allowing downstream genes to inappropriately escape repression. Such mutations would also be worthwhile to assess in study cohorts.

\section{Conclusion}

Animal and human data indicate that maternal folate status could be a biologically plausible risk factor for ASD. Insufficient folate intake can result in DNA hypomethylation, and hypomethylation is associated with neurodevelopment. However, the weight of evidence regarding the role of maternal folate status and the development of ASD is far from unequivocal. Given their limitations in study design, especially with regard to timing of exposure and potential confounding by other vitamins, the randomised trials and studies of maternal folate biomarkers provide little insight into the potential role of FA as a protective factor against ASD traits.

Studies of self-reported maternal FA use and ASD and related traits are inconsistent, providing limited evidence of a protective effect. Nevertheless, methodological limitations exist, including potential confounding by other nutrients and residual confounding by health-related behaviours, and thus these results should be interpreted with caution. However, the two epidemiological studies of FA intake and ASD diagnoses incorporated various sensitivity analyses or controlled for multivitamin use, thereby suggesting reduced susceptibility to confounding.

In light of an apparent rising prevalence along with the profound individual, familial and societal burden of ASD, there is an urgent need to fill in the gaps in what is currently known of the relationship between folate and ASD. To investigate this aetiology most effectively and efficiently, large historical archives of existing prospective, population-based cohorts should be utilised. Complete assessment of maternal functional folate status requires repeated biological measurement of folate, vitamin $B_{12}$ and homocysteine through the first trimester of pregnancy, as well as folate-relevant genetic variants involved in one-carbon metabolism and epigenetic mechanisms. Information on dietary and supplemental intake ideally would be available to relate measures of folate status in a large population, and aid in interpretation of existing studies utilising measures of self-report. Children's ASD diagnoses should be assessed from a clinical source, with high levels of case ascertainment.

As ASD is complex, heterogeneous and multi-causal, exploring environmental influences in conjunction with functionally relevant genes may help identify an additional subset of causes for which genetic contributions may be indirect. If one-carbon metabolism is involved in the aetiology of ASD, this provides a potential route for prevention through nutritional intervention in the pre- and peri-conceptional periods, especially for the subgroup of children having specific genetic risk factors for ASD.

\section{Acknowledgements}

The authors thank Connor Kerns for assistance in management of manuscript scope.

This research received no specific grant from any funding agency, commercial or not-for-profit sectors.

E. A. D. and B. K. L. conceptualised and designed the study, drafted the manuscript and approved the final manuscript. R. M. G. and C. J. N. reviewed and revised the manuscript, and approved the final manuscript.

There are no conflicts of interest.

\section{References}

1. Levy SE \& Mandell D (2009) Autism. Lancet 374, 1627-1638.

2. Baio J (2012) Prevalence of autism spectrum disorders: Autism and Developmental Disabilities Monitoring Network, 14 sites, United States, 2008. MMWR Surveill Summ 61, 1-19.

3. Gaugler T, Klei L, Sanders SJ, et al. (2014) Most genetic risk for autism resides with common variation. Nat Genet 46, 881-885.

4. Sandin S, Lichtenstein P, Kuja-Halkola R, et al. (2014) The familial risk of autism. JAMA 311, 1770-1777.

5. Schmidt RJ, Tancredi DJ, Ozonoff S, et al. (2012) Maternal periconceptional folic acid intake and risk of autism spectrum disorders and developmental delay in the CHARGE (CHildhood Autism Risks from Genetics and Environment) casecontrol study. Am J Clin Nutr 96, 80-89.

6. Suren P, Roth C, Bresnahan M, et al. (2013) Association between maternal use of folic acid supplements and risk of autism spectrum disorders in children. JAMA 309, 570-577. 
7. Wald N (1991) Prevention of neural tube defects - results of the Medical Research Council Vitamin Study. Lancet 338 , 131-137.

8. Williams J, Mai CT, Mulinare J, et al. (2015) Updated estimates of neural tube defects prevented by mandatory folic acid fortification - United States, 1995-2011. MMWR Morb Mortal Wkly Rep 64, 1-5.

9. Maestro S, Muratori F, Cesari A, et al. (2005) Course of autism signs in the first year of life. Psychopathology 38, 26-31.

10. Maestro S, Muratori F, Cavallaro MC, et al. (2002) Attentional skills during the first 6 months of age in autism spectrum disorder. J Am Acad Child Adolesc Psychiatry 41, 1239-1245.

11. Schaevitz LR \& Berger-Sweeney JE (2012) Gene-environment interactions and epigenetic pathways in autism: the importance of one-carbon metabolism. ILAR J 53, 322-340.

12. Haaf $\mathrm{T}$ (2006) Methylation dynamics in the early mammalian embryo: implications of genome reprogramming defects for development. Curr Top Microbiol Immunol 310, 13-22.

13. Mayer W, Niveleau A, Walter J, et al. (2000) Embryogenesis demethylation of the zygotic paternal genome. Nature $\mathbf{4 0 3}$, 501-502

14. Geiman TM \& Muegge K (2010) DNA methylation in early development. Mol Reprod Dev 77, 105-113.

15. Rice D \& Barone S Jr (2000) Critical periods of vulnerability for the developing nervous system: evidence from humans and animal models. Environ Health Perspect 108, 511-533.

16. Zeisel SH (2011) The supply of choline is important for fetal progenitor cells. Semin Cell Dev Biol 22, 624-628.

17. LaSalle JM (2011) A genomic point-of-view on environmental factors influencing the human brain methylome. Epigenetics $\mathbf{6}$, 862-869.

18. Li E, Bestor TH \& Jaenisch R (1992) Targeted mutation of the DNA methyltransferase gene results in embryonic lethality. Cell 69, 915-926.

19. Okano M, Bell DW, Haber DA, et al. (1999) DNA methyltransferases Dnmt3a and Dnmt3b are essential for de novo methylation and mammalian development. Cell 99, 247-257.

20. Niculescu MD, Craciunescu CN \& Zeisel SH (2006) Dietary choline deficiency alters global and gene-specific DNA methylation in the developing hippocampus of mouse fetal brains. FASEB J 20, 43-49.

21. Armstrong D, Dunn JK, Antalffy B, et al. (1995) Selective dendritic alterations in the cortex of Rett syndrome. J Neuropath Exp Neur 54, 195-201.

22. Kishi N \& Macklis JD (2010) MeCP2 functions largely cell-autonomously, but also non-cell-autonomously, in neuronal maturation and dendritic arborization of cortical pyramidal neurons. Exp Neurol 222, 51-58.

23. Dominguez-Salas P, Moore SE, Baker MS, et al. (2014) Maternal nutrition at conception modulates DNA methylation of human metastable epialleles. Nat Commun 5, 3746.

24. Christman JK, Sheikhnejad G, Dizik M, et al. (1993) Reversibility of changes in nucleic acid methylation and gene expression induced in rat liver by severe dietary methyl deficiency. Carcinogenesis 14, 551-557.

25. Chango A, Boisson F, Barbe F, et al. (2000) The effect of $677 \mathrm{C}->\mathrm{T}$ and $1298 \mathrm{~A}->\mathrm{C}$ mutations on plasma homocysteine and 5, 10-methylenetetrahydrofolate reductase activity in healthy subjects. Br J Nutr $\mathbf{8 3}, 593-596$.

26. $\mathrm{Pu} \mathrm{D}$, Shen $\mathrm{Y} \& \mathrm{Wu} \mathrm{J}$ (2013) Association between MTHFR gene polymorphisms and the risk of autism spectrum disorders: a meta-analysis. Autism Res 6, 384-392.

27. Steinfeld R, Grapp M, Kraetzner R, et al. (2009) Folate receptor alpha defect causes cerebral folate transport deficiency: a treatable neurodegenerative disorder associated with disturbed myelin metabolism. Am J Hum Genet 85, 354-363.
28. Miller AL (2008) The methylation, neurotransmitter, and antioxidant connections between folate and depression. Altern Med Rev 13, 216-226.

29. Chugani DC, Muzik O, Behen M, et al. (1999) Developmental changes in brain serotonin synthesis capacity in autistic and nonautistic children. Ann Neurol 45, 287-295.

30. El-Ansary AK, Ben Bacha AG \& Al-Ayahdi LY (2011) Impaired plasma phospholipids and relative amounts of essential polyunsaturated fatty acids in autistic patients from Saudi Arabia. Lipids Health Dis 10, 63.

31. Mattson MP \& Shea TB (2003) Folate and homocysteine metabolism in neural plasticity and neurodegenerative disorders. Trends Neurosci 26, 137-146.

32. Craciunescu CN, Brown EC, Mar M-H, et al. (2004) Folic acid deficiency during late gestation decreases progenitor cell proliferation and increases apoptosis in fetal mouse brain. J Nutr 134, 162-166.

33. Greenblatt JM, Huffman LC \& Reiss AL (1994) Folic-acid in neurodevelopment and child-psychiatry. Prog Neuropsychopharmacol Biol Psychiatry 18, 647-660.

34. Schaevitz L, Berger-Sweeney J \& Ricceri L (2014) One-carbon metabolism in neurodevelopmental disorders: using broadbased nutraceutics to treat cognitive deficits in complex spectrum disorders. Neurosci Biobehav Rev 46, 270-284.

35. Braun JM, Froehlich T, Kalkbrenner A, et al. (2014) Brief report: are autistic-behaviors in children related to prenatal vitamin use and maternal whole blood folate concentrations? J Autism Dev Disord 44, 2602-2607.

36. Steenweg-de Graaff J, Ghassabian A, Jaddoe VW, et al. (2015) Folate concentrations during pregnancy and autistic traits in the offspring. The Generation R Study. Eur J Public Health 25, 431-433.

37. Roth C, Magnus P, Schjolberg S, et al. (2011) Folic acid supplements in pregnancy and severe language delay in children. JAMA 306, 1566-1573.

38. Julvez J, Fortuny J, Mendez M, et al. (2009) Maternal use of folic acid supplements during pregnancy and four-year-old neurodevelopment in a population-based birth cohort. Paediatr Perinat Epidemiol 23, 199-206.

39. Wehby GL \& Murray JC (2008) The effects of prenatal use of folic acid and other dietary supplements on early child development. Matern Child Health J 12, 180-187.

40. Veena SR, Krishnaveni GV, Srinivasan K, et al. (2010) Higher maternal plasma folate but not vitamin B-12 concentrations during pregnancy are associated with better cognitive function scores in 9-to 10-year-old children in South India. J Nutr 140, 1014-1022.

41. Christian P, Murray-Kolb LE, Khatry SK, et al. (2010) Prenatal micronutrient supplementation and intellectual and motor function in early school-aged children in Nepal. $J$ Am Med 304, 2716-2723.

42. Dobo M \& Czeizel A (1998) Long-term somatic and mental development of children after periconceptional multivitamin supplementation. Eur J Pediatr 157, 719-723.

43. Division of Birth Defects - National Center on Birth Defects and Developmental Disabilities, Centers for Disease Control and Prevention (2013) Autism spectrum disorders data \& statistics. http://www.cdc.gov/ncbddd/autism/documents/ asd_prevalence_table_2013.pdf (accessed 15 October 2013).

44. Lawlor DA, Davey Smith G, Kundu D, et al. (2004) Those confounded vitamins: what can we learn from the differences between observational versus randomised trial evidence? Lancet 363, 1724-1727.

45. Pouchieu C, Levy R, Faure C, et al. (2013) Socioeconomic, lifestyle and dietary factors associated with dietary supplement use during pregnancy. PLOS ONE 8, e70733. 
46. Tinker SC, Hamner HC, Berry RJ, et al. (2012) Does obesity modify the association of supplemental folic acid with folate status among nonpregnant women of childbearing age in the United States? Birth Defects Res A Clin Mol Teratol 94, 749-755.

47. Avalos LA, Kaskutas LA, Block G, et al. (2009) Do multivitamin supplements modify the relationship between prenatal alcohol intake and miscarriage? Am J Obstet Gynecol 201, 563.e1-563.e9.

48. Wu TJ, Buck G \& Mendola P (1998) Can regular multivitamin/ mineral supplementation modify the relation between maternal smoking and select adverse birth outcomes? Ann Epidemiol 8, 175-183.

49. Bjorke-Monsen AL, Roth C, Magnus P, et al. (2013) Maternal B vitamin status in pregnancy week 18 according to reported use of folic acid supplements. Mol Nutr Food Res 57, 645-652.

50. Schmidt RJ, Tancredi DJ, Krakowiak P, et al. (2014) Maternal intake of supplemental iron and risk of autism spectrum disorder. Am J Epidemiol 180, 890-900.

51. Lyall K, Munger KL, O'Reilly ÉJ, et al. (2013) Maternal dietary fat intake in association with autism spectrum disorders. $A m J$ Epidemiol 178, 209-220.

52. Steenweg-de Graaff J, Roza SJ, Steegers EA, et al. (2012) Maternal folate status in early pregnancy and child emotional and behavioral problems: the Generation R Study. Am J Clin Nutr 95, 1413-1421.

53. Schlotz W, Jones A, Phillips DI, et al. (2010) Lower maternal folate status in early pregnancy is associated with childhood hyperactivity and peer problems in offspring. J Child Psychol Psychiatry 51, 594-602.

54. McNulty B, Pentieva K, Marshall B, et al. (2011) Women's compliance with current folic acid recommendations and achievement of optimal vitamin status for preventing neural tube defects editorial comment. Obstet Gynecol Surv 66, 541-542.

55. Brough L, Rees GA, Crawford MA, et al. (2009) Social and ethnic differences in folic acid use preconception and during early pregnancy in the UK: effect on maternal folate status. J Hum Nutr Diet 22, 100-107.

56. Pietruszka B \& Brzozowska A (2006) Folic acid supplementation practice in Europe - plenary lecture. Pol J Food Nutr Sci 15/56, 93-99.

57. Sadler TW (2011) Langman's Medical Embryology. Philadelphia: Lippincott Williams \& Wilkins.

58. Ghishan FK, Said HM, Wilson PC, et al. (1986) Intestinal transport of zinc and folic-acid - a mutual inhibitory effect. $\mathrm{Am}$ J Clin Nutr 43, 258-262.
59. Milne DB, Canfield WK, Mahalko JR, et al. (1984) Effect of oral folic-acid supplements on zinc, copper, and iron-absorption and excretion. Am J Clin Nutr 39, 535-539.

60. Anonymous (1992) Recommendations for the use of folic acid to reduce the number of cases of spina bifida and other neural tube defects. MMWR Recomm Rep 41, 1-7.

61. Lawrence JM, Bpetitti D, Watkins M, et al. (1999) Trends in serum folate after food fortification. Lancet 354, 915-916.

62. King M \& Bearman P (2009) Diagnostic change and the increased prevalence of autism. Int J Epidemiol 38, 1224-1234.

63. Shattuck PT (2006) The contribution of diagnostic substitution to the growing administrative prevalence of autism in US special education. Pediatrics 117, 1028-1037.

64. Liu K-Y, King M \& Bearman PS (2010) Social influence and the autism epidemic. Am J Soc 115, 1387-1434.

65. Liu K, Zerubavel N \& Bearman P (2010) Social demographic change and autism. Demography 47, 327-343.

66. King MD, Fountain C, Dakhlallah D, et al. (2009) Estimated autism risk and older reproductive age. Am J Public Health 99, 1673-1679.

67. Rogers EJ (2008) Has enhanced folate status during pregnancy altered natural selection and possibly autism prevalence? A closer look at a possible link. Med Hypotheses 71, 406-410.

68. Mayor-Olea A, Callejon G, Palomares AR, et al. (2008) Human genetic selection on the MTHFR $677 \mathrm{C}>\mathrm{T}$ polymorphism. BMC Med Genet 9, 104.

69. Guo T, Chen H, Liu B, et al. (2012) Methylenetetrahydrofolate reductase polymorphisms $\mathrm{C} 677 \mathrm{~T}$ and risk of autism in the Chinese Han population. Genet Test Mol Biomarkers 16, 968-973.

70. Boris M, Goldblatt A, Galanko J, et al. (2004) Association of MTHFR gene variants with autism. J Am Physicians Surg 9, 106-108.

71. Black MM (2008) Effects of vitamin B12 and folate deficiency on brain development in children. Food Nutr Bull 29, S126-S131.

72. Kalmbach RD, Choumenkovitch SF, Troen AP, et al. (2008) A 19-base pair deletion polymorphism in dihydrofolate reductase is associated with increased unmetabolized folic acid in plasma and decreased red blood cell folate. J Nutr $\mathbf{1 3 8}$, 2323-2327.

73. Schirch L \& Peterson D (1980) Purification and properties of mitochondrial serine hydroxymethyltransferase. $J$ Biol Chem 255, 7801-7806. 